\title{
PHYTOCHEMICAL ANALYSIS AND COMPARATIVE ANTIPARKINSON ACTIVITY OF FOUR SPECIES OF MUCUNA
}

\author{
KARUNANITHI M ${ }^{1 *}$, DAVID RAJ C ${ }^{1}$, BRINDHA P1 , JEGADEESAN M², KAVIMANI S ${ }^{3}$
}

${ }^{1}$ Centre for Advanced Research in Indian System of Medicine, Shanmugha Arts, Science, Technology and Research Academy Deemed University, Thanjavur, Tamil Nadu, India. ${ }^{2}$ Department of Environmental Sciences and Medicinal Botany, Tamil University, Thanjavur, Tamil Nadu, India. ${ }^{3}$ Department of Pharmacology, College of Pharmacy, Mother Theresa Post Graduate and Research Institute of Health Sciences, Puducherry, India. Email: karuna@carism.sastra.edu

Received: 06 April 2017, Revised and Accepted: 29 March 2018

\section{ABSTRACT}

Objective: The aim was to study the antiparkinson activity in the seed extracts of four species of Mucuna.

Methods: The hydroalcoholic extracts of seeds of four species of Mucuna were evaluated for antiparkinson activity of after a preliminary phytochemical study. The activity was measured in rats by indirectly measuring the decrease in malondialdehyde level, decrease in tongue protrusion frequency, and reduction in vacuous chewing movement after administering reserpine at the dose of $1 \mathrm{mg} / \mathrm{kg}$. The dose levels of four species of $M u c u n a$ seed extract were kept at 100, 200, and $300 \mathrm{mg} / \mathrm{Kg}$.

Results: Extracts exhibited potent antiparkinson activity and achieved statistically significant p values compared with control group. The study corroborates and compares all four species of Mucuna.

Conclusion: Among the extracts, the highest percentage of antiparkinson activity was recorded for Mucuna pruriens

Keywords: Mucuna pruriens, Cochinchinesis, Utilis, Deeringiana, Antiparkinson activity.

(C) 2018 The Authors. Published by Innovare Academic Sciences Pvt Ltd. This is an open access article under the CCBY license (http://creativecommons org/licenses/by/4. 0/) DOI: http://dx.doi.org/10.22159/ajpcr.2018.v11i7.18959

\section{INTRODUCTION}

Parkinson's disease belongs to a group of conditions called movement disorders. It is characterized by muscle rigidity, tremor, a slowing of physical movement (bradykinesia) and in extreme cases, a loss of physical movement (akinesia) [1]. It is a clinical syndrome characterized by lesions in the basal ganglia, predominantly in the substantia nigra [2]. As a rule, PD begins between the ages of 40 and 70 years, with peak age onset in the seventh decade. The prevalence of PD is approximately 160 cases per 100,000 populations, and the incidence is about 20 cases per 100,000 populations. The pathological changes of PD may appear as early as three decades before the appearance of clinical signs [3]. The cause of PD is probably multifactorial, with contributions from hereditary predisposition, environmental toxins, and aging [4]. The most widely used form of treatment is L-DOPA in various forms. L-DOPA is transferred into dopamine in the dopaminergic neurons by L-aromatic amino acid decarboxylase.

Mucuna pruriens(L.) DC., the velvet bean, is one of the important herbal drugs in the Indian Systems of Medicine. Seeds of this plant contain a high amount of L-DOPA [5]. The seeds are used in the treatment of many common ailments and also as a food. The seeds have been sold in the herbal drug market in many parts of India in the name of "atmagupta" or "poonaikali" [6]. In our survey, we found that seeds of many other species other than M. pruriens are sold as "poonaikali" in Tamil Nadu and "atmagupta" or "kawanch" in other states of India. It is frightening to note that the crude drug traders and traditional physicians and pharmaceutical manufacturers, who use this seed for preparation of medicine, are unaware of its identity and its adulterants. As "poonaikali" is a common drug and big demand in India and abroad, it is essential to standardize the scientific lines for identifying the authentic drug and to detect the adulterants. Although many pharmacological works on seeds of M. pruriens have been carried out, comparative scientific work of $M$. pruriens and its adulterants is not available.
The seeds of $M$. pruriens are reported to have antiparkinson activity along with other activities. Commonly $M$. pruriens is adulterated with other species of the genus such as Mucuna deeringiana, Mucuna utilis, and Mucuna cochinchinesis. This department has worked on seeds of Mucuna and its adulterants on the basic phytochemical and pharmacological works [7]. In this work, we would study comparative and detailed phytochemistry and pharmacology of the seeds of M. pruriens and its adulterants.

\section{MATERIALS AND METHODS}

\section{Collection of seed samples}

Seeds of "poonaikali" (minimum $2 \mathrm{~kg}$ ) were procured from different herbal drug stores in Madurai, Thanjavur, and Chennai. Some of the seed samples were collected from the Herbal Garden of Tamil University.

\section{Preparation of extract}

The collected seed samples were dried in the open sunlight for 2 days. Then, the dried seeds were cleaned. Foreign matter, broken seeds, and immature seeds were removed from the sample. The seeds were stored in a suitable plastic container and kept at room temperature. Then, the seeds were powdered mechanically to 60 mesh size. The seed powder was soaked in $70 \%$ ethanol for $72 \mathrm{~h}$ with occasional shaking. The solvent was decanted and filtered. The marc was subjected to further extraction by repeating the procedure thrice. The solvent was removed by distillation under vacuum. Previous work on the seeds of Mucuna species [7] had revealed the presence of most of the active principles in alcoholic and water extracts. Hence, hydroalcoholic extract was chosen for the analytical and pharmacological study.

\section{Powder analysis}

Behavior of seed powder with different chemical reagents was carried out as mentioned by Kay L [8] Johnson [9] and Birch and Doughty [10]. 
Qualitative phytochemical studies

Qualitative phytochemical analysis was done using the procedure of Kokate (1994). Alkaloids, carbohydrates, tannins and phenols, fixed oils and fats, saponins and gums, and mucilages were qualitatively analyzed.

\section{Quantitative phytochemical studies}

The estimation of total alkaloid was performed by gravimetric method [11] total protein [12], total tannins [13], and total phenolic content [14].

\section{Thin layer chromatography (TLC) studies}

Extracts mixed with $0.1 \mathrm{~N} \mathrm{HCl}$ were spotted on silica gel G coated plates. $\mathrm{N}$-Butanol, glacial acetic acid, and water in the ratio of 2:1:1 was used as mobile phase. Freshly prepared mixture of an equal proportion of $10 \%$ ferric chloride and 5\% potassium ferricyanide was used as detecting agent.

One study was carried out using the above procedure with $M$. pruriens powder and a marketed pharmaceutical product containing Mucuna.

Another study was carried out with four types of extract as four spots and using L-DOPA standard as the fifth spot.

\section{Animal studies}

\section{Antiparkinson activity [15,16]}

Animals

Recently, a promising animal model of tardive dyskinesia has been proposed: The increase in tongue-protrusion frequency induced by repeated administration of reserpine (RE) in rats [17]. In this regard, although RE is not classified as a neuroleptic, it was used as an antipsychotic agent and has been associated with the development of tardive dyskinesia [18]. This RE-induced oral dyskinesia in rats has several other features that are consistent with this movement disorder, including persistence following interrupted administration, and a reported dose-dependent blockade induced by a D2 selective antagonist. As with tardive dyskinesia, RE-induced oral dyskinesia is exacerbated by dopamine agonists like amphetamine [19].

Furthermore, despite the fact that RE-induced tongue-protrusion dyskinesia in rats develops very rapidly (few days) after high doses [20]; this fact offers an outstanding methodological advantage over other proposed rodent models of tardive dyskinesia.

An important hypothesis recently receiving considerable interest is the proposal that the symptoms of Parkinsonism are due to neurotoxic effects of free radical byproducts from dopamine (DA) metabolism. The increase in DA turnover is produced from blockage of dopamine receptors by neuroleptics [21]. Dopamine undergoes monoamine oxidase-catalyzed oxidative deamination to 3,4-dihydroxyphenylacetaldehyde (DOPAL), which is metabolized primarily to 3,4-dihydroxyphenylacetic acid. DOPAL is a reactive radical and toxic to dopaminergic cells [22]. DOPAL injection into the substantia nigra of rats resulted in DA neuron loss [23].

There were 84 male albino mice weighing 20-40 g housed under conditions of controlled temperature $\left(20 \pm 2^{\circ} \mathrm{C}\right)$ and lighting $(12 \mathrm{~h}$ light/12 h dark, lights on at 7:00 am). Food and water were available ad libitum throughout the experiment. The mice were brought to the experimental laboratory 7 days before the beginning of the experiment and immediately housed at random in groups of 6 animals per cage. All procedures involving laboratory animal use were in accordance to the Institute Animal Ethics Committee regulations approved by the Committee for the Purpose of Control and Supervision of Experiments on Animals (CPCSEA).

Drugs

The drugs used in these experiments were obtained from Sigma (St. Louis, MO). RE was dissolved in $50 \mu \mathrm{l}$ of glacial acetic acid and then diluted to the correct concentration with distilled water, and injected at the dose of $1 \mathrm{mg} / \mathrm{kg}$. Vehicle consisted of the same amount of acetic acid and water used in the RE solution. Hydroalcoholic extract of M. pruriens was dissolved in $1 \%$ tween 80 .

\section{Experimental procedures}

Mice were randomly divided into 14 groups of six animals each, which received a hydroalcoholic extract of Mucuna species at the dose of 100 , 200 , and $300 \mathrm{mg} / \mathrm{kg}$ orally for the period of 16 days. On days 14 and 16 , $1 \mathrm{mg} / \mathrm{kg}$ i.p. RE was injected $1 \mathrm{~h}$ after the drug and vehicle treatment. After $24 \mathrm{~h}$ of the last RE injection, all the animals were subjected to behavioral observation as follows:

Animal behavior was initially observed in a glass cage. Mirrors were placed under the floor and behind the back wall of the cage to permit observation of oral movements when the animal faced away from the observer. In this experimental stage, oral movement and tremor were observed. The frequency of tongue protrusion and vacuous chewing movements (VCM) was determined using hand-operated counters. In the present study, tongue protrusion was operationally defined as a visible extension of the tongue outside of the mouth and not directed at anything. Individual tongue protrusions during a short time of oral dyskinesia were each preceded by visible retraction of the tongue [19]. If tongue protrusions occurred during a period of grooming, they were not taken into account. The incidence of tongue protrusions was measured continuously for $10 \mathrm{~min}$. VCMs were scored during $5 \mathrm{~min}$ observation period, according to a five-point scale $(0=$ absent, 1 =minimal, $2=$ mild, $3=$ moderate, and $4=$ severe $)$. A VCM consisted of a rapid movement of the jaw which resembles chewing but did not appear to be directed at any particular stimulus [24].

Stopwatches were used to quantify the duration of generalized body tremor, expressed in seconds. These parameters were measured continuously for $15 \mathrm{~min}$.

The animal's forepaws were then placed on a horizontal glass bar ( $2 \mathrm{~mm}$ diameter) elevated $4.5 \mathrm{~cm}$ above the observation floor, and the time elapsing before the animal removed its forepaws from the bar and placed them on the floor was measured. This test was repeated 3 times during a session, with the longest elapsed time representing the catalepsy score, expressed in seconds [25].

\section{Statistical analysis}

Statistical analysis was performed with GraphPad Prism 5 Software (GraphPad Prism Software Inc. San Diego, California, USA). VCMs and tongue protrusions are considered to be nonparametric. Thus, the data were analyzed by Kruskal-Wallis analysis of variance followed by the Dunn's Multiple Comparisons test. Tremor and catalepsy are considered to be parametric, and the data were analyzed by ANOVA followed by the Tukey test. A probability of $\mathrm{p}<0.05$ was considered to show significant differences for all comparisons made.

\section{RESULTS}

\section{Morphology of seeds}

Seeds of different samples of Mucuna spp. were purchased from different places of Tamil Nadu such as Madurai, Thanjavur, and Chennai. Botanical identity of the samples was established based on the morphology of the seeds (plates 1-4).

Morphological description and dimensions of seeds of different samples are given in Table 1 (plates 1-4). Color of the seeds, weight/100 seeds, dimensions of seeds, thickness of seed coat, dimensions of raphae, thickness of cotyledon, and loss on drying were noted (Fig. 1).

The seeds of M. pruriens and its adulterants could be distinguished by their size and shape. Thus seeds of M. pruriens, M. cochinchinensis, and $M$. deeringiana are oval in shape and smooth and glossy. Seeds of M. utilis are angular in shape and smooth and glossy. On the basis of the dimensions, the seeds of mucuna species could be grouped as medium 
and small. M. deeringinana and M. utilis are medium in size followed by M. cochinchinensis. Among all the seed samples, M. pruriens seeds are the smallest.

Weight of 100 seeds of the four samples has correlation to their size class. Thus, among the medium-sized class seeds (M. deeringiana and M. utilis), M. deeringiana has the highest weight. Even though $M$. cochinchinensis is smaller in size the weight of 100 seeds is slightly higher in proportion. M. pruriens seeds have lowest weight/100 seeds, among all the samples (Table 1).

\section{Analytical values}

Analytical values such as total ash, acid insoluble ash, acid soluble ash, and solubility percentage in water for all the four samples were analyzed, and their values are tabulated in Table 2 . Total ash value is more or less same in all seed samples. M. utilis has slightly higher ash value. Acid-insoluble ash value is the highest (0.1222) in M. utilis and is lowest in M. deeringiana (0.0588\%), medium values in M. pruriens, and M. cochinchinensis were noted. Value of solubility percentage in water was higher for M. pruriens seeds.

\section{Qualitative phytochemical studies}

Qualitative phytochemical analysis for alkaloids, carbohydrates tannins, phenols, gums and mucilage, fixed oils and fats, saponins and steroids was screened in four types of seed samples and was recorded in Table 4. Extractive values in solvents yielded distinct values for the four seed samples. M. deeringiana and M. utilis did not have any extractive value in pet ether. All the seed samples had higher extractive values in water followed by an alcohol. Lower values were observed for all the samples in chloroform. The order of extractive values in alcohol is $\mathrm{MD}>\mathrm{MU}>\mathrm{MC}>\mathrm{MP}$; and in water $\mathrm{MU}>\mathrm{MC}>\mathrm{MP}>\mathrm{MD}$; and in benzene $\mathrm{MD}>\mathrm{MU}>\mathrm{MC}>\mathrm{MP}$ (Table 3 ).

\section{Alkaloids}

Presence of alkaloids was noted in all the seed samples in benzene, chloroform, alcohol, and aqueous extracts. Out of the four extracts, aqueous extracts of the samples gave more amounts of alkaloids followed by benzene extracts.

\section{Preparation of hydroalcoholic extract}

The collected seed samples were thoroughly shade dried for 2 days. Then, the dried seeds were cleaned and any foreign matter, broken seeds and immature seeds were removed. The seeds were stored in a plastic container at room temperature. Then, the seeds were powdered separately in a mechanical way to 60 mesh size. The seed powder was soaked in $70 \%$ ethanol for $72 \mathrm{~h}$ with occasional shaking. The solvent was decanted and filtered. The marc was subjected to further extraction by repeating the procedure thrice. The solvent was removed from the extract by vacuum distillation.

\section{Quantitative phytochemical studies}

\section{Estimation of protein, carbohydrate, and alkaloids}

Total protein, carbohydrate, and alkaloids in seeds of M. pruriens and its adulterants were estimated. Highest protein content (32\%) was obtained in dried samples of M. pruriens followed by M. utilis (28\%). Lowest protein content (25\%) was observed in M. cochinchinensis seeds.

Maximum carbohydrates content (53\%) was observed in M. deeringiana followed by M. pruriens (41\%). In M. utilis lowest carbohydrate (40\%) was observed.

Total alkaloids of seed samples reveal highest content (0.82\%) in M. utilis. Alkaloid content in seeds is in the following order: $\mathrm{MU}>\mathrm{MP}>\mathrm{MD}>\mathrm{MC}$

Phenols and tannin are present in seeds of M. pruriens, and its adulterants were estimated (Table 5). Highest phenol content (6.63\%) was observed in M. utilis. M. cochinchinensis showed lowest (2.13\%) phenol content and M. pruriens seeds had 2.15\%.

Estimation of tannins in seeds showed the highest value $(2.1 \%)$ in M. deeringiana. M. pruriens had $0.3 \%$ of tannins.

Table 1: Macroscopic details of seeds of $M$. pruriens and its adulterants

\begin{tabular}{lllll}
\hline S. No & Parameters & M. pruriens & M. cochinchinensis & M. deeringinana \\
\hline 1 & Color & Black & Dull white & Black \\
2 & Weight $/ 100$ seeds (gm) & 32.72 & 90.64 & 162.14 \\
3 & Dimensions of seed & $12 \times 9 \times 6$ & $14 \times 10 \times 7$ & $16 \times 11 \times 8$ \\
& L $\times$ B $\times$ T (mm) & & & 122.36 \\
4 & Thickness of seed coat (mm) & 0.20 & 0.25 & 0.17 \\
5 & Dimensions of raphae LxB & $5 \times 2$ & $7 \times 2$ & $6 \times 2$ \\
6 & Thickness of cotyledon (mm) & 5.32 & 6.08 & 7.61 \\
7 & LOD (\%) & 5.71 & 7.13 & 3.54 \\
\hline
\end{tabular}

M. pruriens: Mucuna pruriens, M. cochinchinensis: Mucuna cochinchinensis, M. deeringinana: Mucuna deeringinana, M. utilis: Mucuna utilis

Table 2: Analytical values (in percentage) of seed powders

\begin{tabular}{lllll}
\hline S. No & Parameters & M. pruriens & M. cochinchinensis & M. deeringinana \\
\hline 1 & Total ash value & 3.2732 & 3.0728 & 3.0553 \\
2 & Acid-insoluble ash value & 0.0854 & 0.1231 & 0.0588 \\
3 & Acid soluble ash value & 3.1878 & 2.9497 & 2.9965 \\
4 & Solubility percentage in alcohol & 3.0000 & 2.9600 & 6.9200 \\
5 & Solubility percentage in water & 25.5300 & 21.2900 & 1222 \\
\hline
\end{tabular}

M. pruriens: Mucuna pruriens, M. cochinchinensis: Mucuna cochinchinensis, M. deeringinana: Mucuna deeringinana, M. utilis: Mucuna utilis

Table 3: Successive extractive values of seeds in percentage

\begin{tabular}{lllllll}
\hline S. No. & Name of the samples & Benzene & Pet ether & Chloroform & Alcohol & Water \\
\hline 1 & M. pruriens & 1.932 & 0.014 & 0.106 & 0.857 & 10.059 \\
2 & M. cochinchinesis & 2.634 & 0.354 & 0.226 & 1.697 & 11.021 \\
3 & M. deeringiana & 5.086 & - & 0.569 & 17.354 & 7.499 \\
4 & M. utilis & 4.269 & - & 1.011 & 5.856 & 12.555 \\
\hline
\end{tabular}

M. pruriens: Mucuna pruriens, M. cochinchinensis: Mucuna cochinchinensis, M. deeringinana: Mucuna deeringinana, M. utilis: Mucuna utilis 
Table 4: Qualitative phytochemical screening of hydroalcoholic extracts of seeds

\begin{tabular}{|c|c|c|c|c|c|}
\hline Alkaloids & Reagent/test & M. pruriens & M. cochinchinensis & M. deeringinana & M. utilis \\
\hline & Mayer's reagent & + & + & + & + \\
\hline & Dragendorff's reagent & + & + & + & + \\
\hline & Hager's reagent & + & - & - & - \\
\hline & Wagner's reagent & + & - & + & - \\
\hline & Mayer's reagent & + & + & + & + \\
\hline & Dragendorff's reagent & + & + & + & + \\
\hline & Hager's reagent & + & + & + & + \\
\hline \multirow[t]{3}{*}{ Carbohydrate } & Molisch's reagent & + & + & + & + \\
\hline & Fehling's reagent & - & - & - & - \\
\hline & Benedict's reagent & + & + & + & + \\
\hline \multirow[t]{3}{*}{ Tannins and phenols } & Ferric chloride & + & + & + & + \\
\hline & Gelatin Solution & + & - & + & + \\
\hline & Lead acetate & + & + & + & + \\
\hline Gums and mucilage & Precipitation test & + & + & + & + \\
\hline Fixed oils and fats & Paper pressing & + & + & + & + \\
\hline
\end{tabular}

+: Presence, -: Absence. M. pruriens: Mucuna pruriens, M. cochinchinensis: Mucuna cochinchinensis, M. deeringinana: Mucuna deeringinana, M. utilis: Mucuna utilis

Table 5: Quantitative estimation of protein, carbohydrate, alkaloids, phenols, and tannins

\begin{tabular}{|c|c|c|c|c|c|c|}
\hline S. No & Name of the samples & Protein (\%) & Carbohydrate (\%) & Alkaloids (\%) & Phenols (\%) & Tannin (\%) \\
\hline 1 & M.pruriens & 32 & 41 & 0.48 & 2.15 & 0.3 \\
\hline 2 & M. cochinchinesis & 25 & 41 & 0.13 & 2.13 & 0.6 \\
\hline 3 & M. deeringiana & 27 & 53 & 0.45 & 5.31 & 2.1 \\
\hline 4 & M. utilis & 28 & 40 & 0.82 & 6.63 & 1.3 \\
\hline
\end{tabular}

M. pruriens: Mucuna pruriens, M. cochinchinensis: Mucuna cochinchinensis, M. deeringinana: Mucuna deeringinana, M. utilis: Mucuna utilis

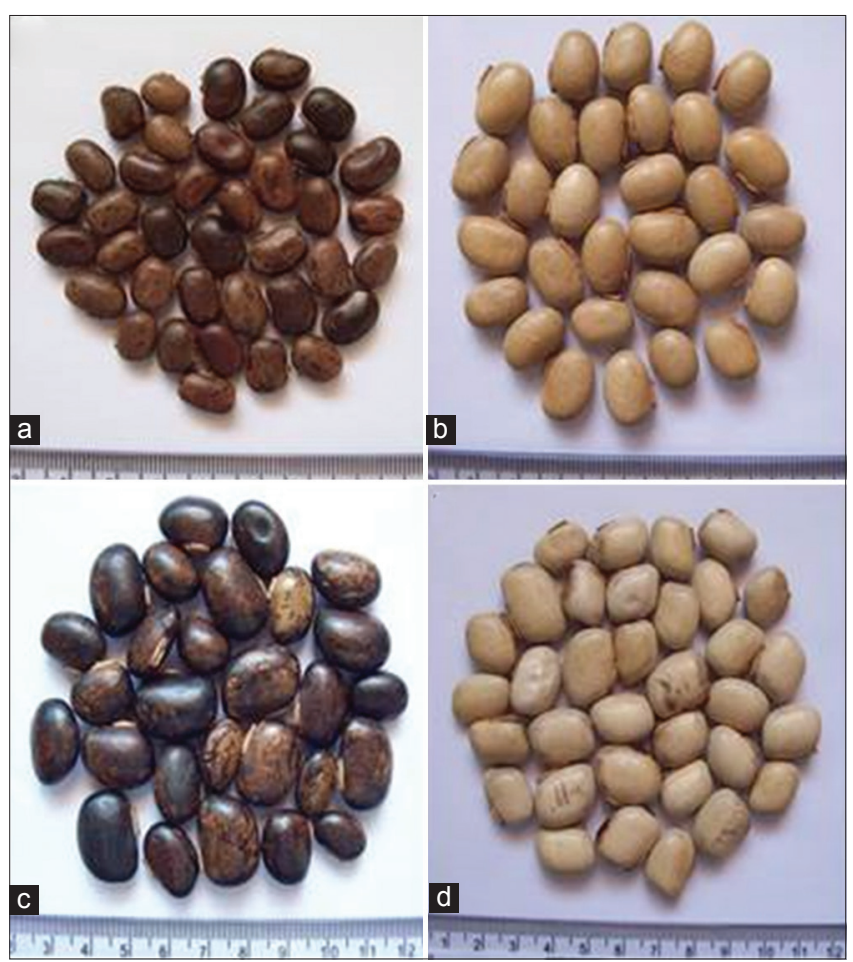

Fig. 1: Morphology of seeds. (a) Seeds of Mucuna pruriens,

(b) seeds of Mucuna cochinchinensis, (c) seeds of Mucuna deeringiana, and (d) seeds of Mucuna utilis

TLC

Coenzyme Q10 by TLC

Hydroalcoholic extracts of all the four species were spotted and compared with the coenzyme $Q_{10}$ as the fifth spot in two solvent systems dioxane: water (50:50) and chloroform: methanol (55:45).
Spots in the four extracts and the standard confirmed the presence of coenzyme $Q_{10}$ at $254 \mathrm{~nm} 366 \mathrm{~nm}$ and after color development. The hydroalcoholic extract was dissolved in chloroform, and it is used for TLC analysis. The solvent systems used were dioxane: water (50:50) and chloroform: methanol (55:45). The spraying reagent used was 5\% phosphomolybdic acid in ethanol. The developed blue colored spots were visualized after spraying $5 \%$ phosphomolybdic acid in ethanol.

\section{Antiparkinson activity}

Antiparkinson activity is measured indirectly by the following activity:

1. Decrease in malondialdehyde (MDA) level

2. Decrease in tongue protrusion frequency (TPF) and

3. Decrease in VCM.

The effect of hydroalcoholic extracts of MC, MD, MP, and MU was observed in the above activity and data recorded (Figs. 2-4).

Free oxygen radicals can induce lipid peroxidation in cells; MDA is formed during oxidative degeneration and accepted as an indicator of lipid peroxidation. RE increased the level of lipid peroxide, MDA, from $1.2 \pm 0.1125$ to $2.5 \pm 0.175$ ( $\mu \mathrm{mol} / \mathrm{g}$ tissue). MP and MD at the dose of $300 \mathrm{mg} / \mathrm{kg}$ prevented the RE-induced elevation in MDA levels and significantly $(\mathrm{p}<0.01)$ decreased its elevated levels to $1.4 \pm 0.1025$ and $1.5 \pm 0.0875$ respectively (Fig. 2), when compared with disease control group. MU treated group does not produce a significant change in MDA levels when compared with RE alone treated group.

Extracts of MC, MD, MP, and MU were administered at three different dosages $(100,200$, and $300 \mathrm{mg} / \mathrm{Kg}$ ) and TPF was observed (Fig. 3). It was noted that TPF was increased three-fold in the control group. There was a dose-dependent response for all the four extracts in decreasing the TPF. TPF was significantly reduced by an extract of MC, MD,and MU and more significantly reduced by MP at the dose of $300 \mathrm{mg} / \mathrm{Kg}$.

Effect of hydroalcoholic extract of MC, MD, MP, and MU on VCM frequency is shown in Fig. 4. Animals that received RE exhibited an 


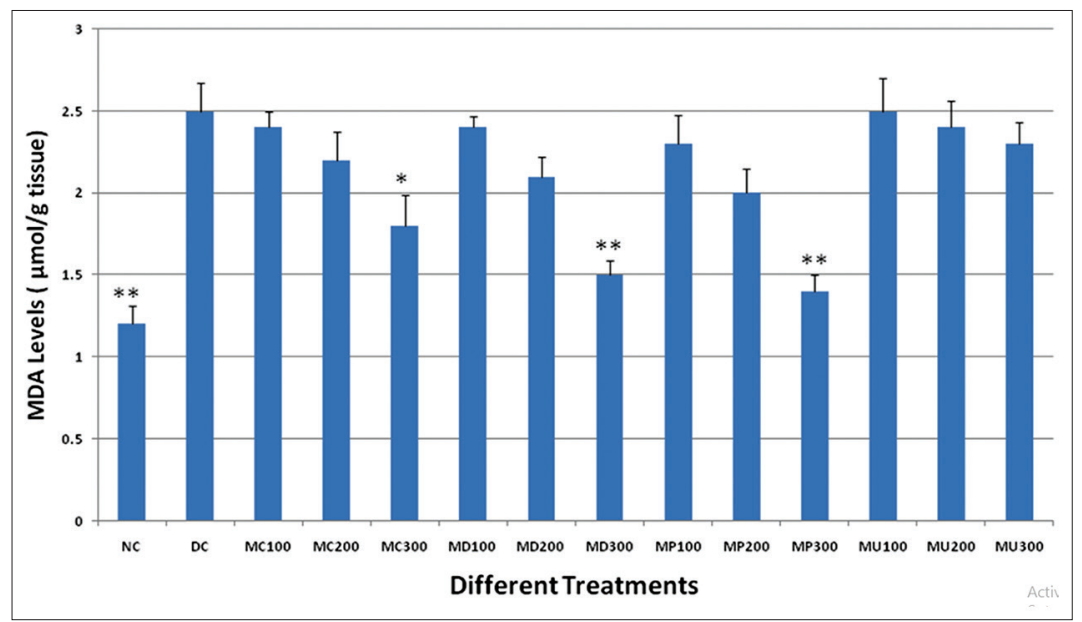

Fig. 2: Effect of extracts of MC, MD, MP, and MU on malondialdehyde. The values are in mean \pm standard error of the mean, $\mathrm{n}=6$, ${ }^{*} \mathrm{p}<0.05$ and ${ }^{* *} \mathbf{p}<0.01$ compared with disease control group

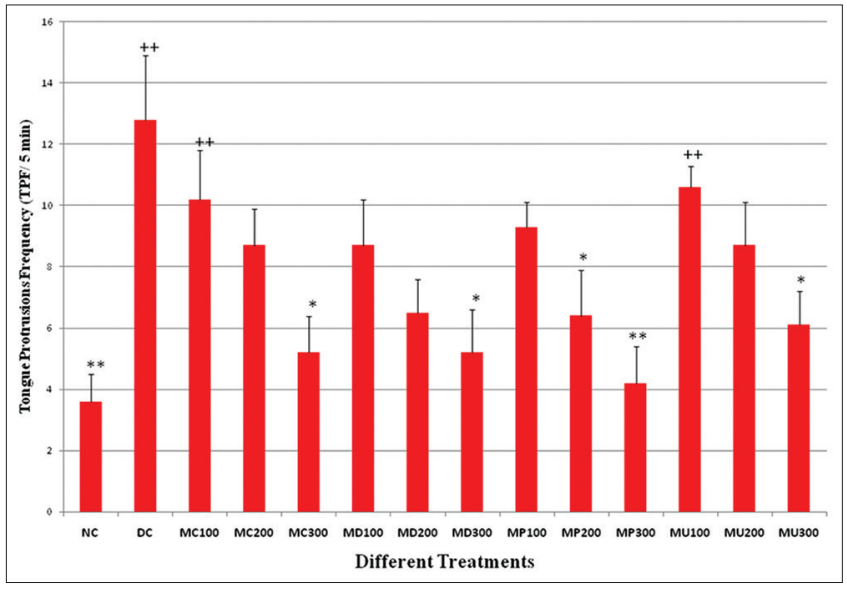

Fig. 3: Effect of extracts of MC, MD, MP, and MU on tongue protrusion frequency. The values are in mean \pm standard error of the mean, $n=6,{ }^{*} p<0.05$ and ${ }^{* *} p<0.01$ compared with disease control group. $++p<0.01$ compared with normal control group

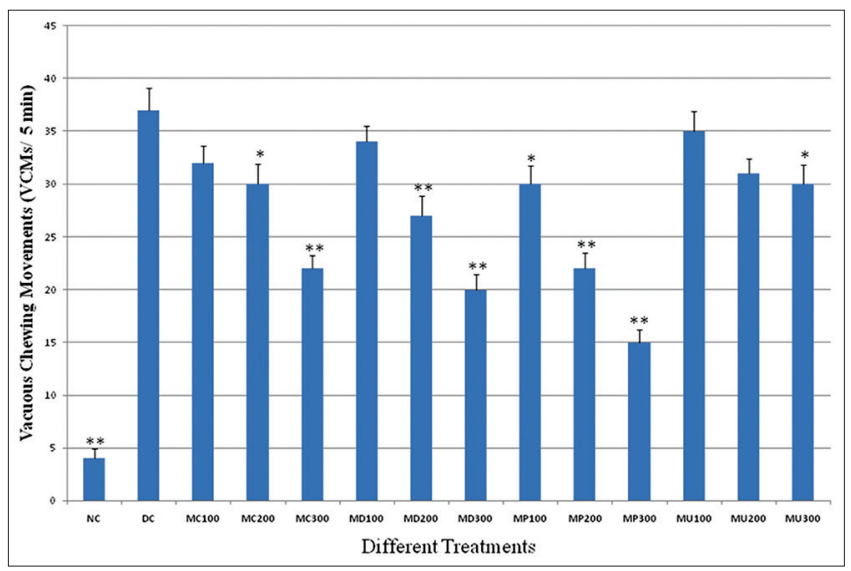

Fig. 4: Effect of extracts of MC, MD, MP, and MU on vacuous chewing movement. The values are in mean \pm standard error of the mean, $n=6,{ }^{*} \mathrm{p}<0.05$ and ${ }^{* *} \mathrm{p}<0.01$ compared with disease control group

increase in VCMs compared to vehicle-treated animals $(\mathrm{p}<0.01)$. All the Mucuna species except MU produced dose-dependent effect. MC, MD, and MP at the dose of $200 \mathrm{mg} / \mathrm{kg}$ showed less significant $(\mathrm{p}<0.01)$ decrease in VCM, when compared with diseased control, whereas MU at the dose of $300 \mathrm{mg} / \mathrm{kg}$ showed significant $(\mathrm{p}<0.05)$ reduction in VCM, when compared with RE alone treated group.

\section{DISCUSSION}

The macroscopic study of the M. pruriens and the adulterants shows the difference in size, color, and weight. The phytochemical study reveals the presence of alkaloids, carbohydrate, tannins, Phenols, gums, mucilages, fixed oils, and saponins. The high-performance TLC was carried out after dissolving extracts in $0.1 \mathrm{~m}$ hydrochloric acid in methanol. The four species were kept as $1-4$ tracks and the $5^{\text {th }}$ track was standard L-DOPA.

The last track is of the reference standard L-DOPA showing a single peak at the $R_{\mathrm{f}}$ value of same 0.43 . This confirms the presence of L-DOPA in all varieties and the only difference in the quantification.

RE interferes with the storage of dopamine (and also of noradrenaline and 5-hydroxytryptamine) in synaptic vesicles, leading to depletion of dopamine in nerve terminals. Its central action produces sedation, hypokinesia, rigidity (catalepsy), and often tremor [26,27]. The effect of RE on spontaneous locomotor activity is frequently used as a model of the motor disturbance of Parkinson's disease [28-30] and several clinically used antiparkinson drugs (e.g., dopamine receptor agonists, L-DOPA + benserazide, amantadine, and trihexyphenidyl) have been shown to improve this motor impairment [30]. This suggests that the RE model showed good face and predictive validity [31]. M. pruriens increased brain dopamine level [32]. Fachinetto and colleagues [33] have reported that animals with VCMs have significantly higher lipid peroxide expressed as thiobarbituric acid reactive substances in the striatum, suggesting increased lipid peroxidation, and free radical production in these animals.

Another source of neuronal oxidative damage is related to calcium overload. It was hypothesized that prolonged stimulation of $\mathrm{N}$-methylD-aspartate (NMDA) and glutamate receptors can induce massive cell death in the brain (excitotoxicity), by causing calcium overload in postsynaptic neurons [34]. Hernández-Fonseca et al. [35] have reported that calcium influx through NMDA receptors is involved in reactive oxygen species (ROS) production and neuronal damage. Lipid peroxidation is considered as a major mechanism of oxygen radical toxicity, thereby altering membrane permeability. Persistent activation of NMDA and non-NMDA glutamate ionotropic receptors mediates calcium entry and ROS production which is well-recognized perpetrators of neuronal oxidative damage [36]. Calcium channel blockers also prevent calciumoverload in ischemic rat brains through their effect on the L-type calcium channel leading to suppression of formation of oxygen-derived free radicals and lipid peroxidation [37]. Our results show that Mucuna species markedly reduced the elevated lipid peroxide levels, MDA, that 
were augmented after RE treatment. The elevated MDA level is better reduced by $M$. pruriens extract when the second highest activity goes to $M$. deeringiana. M. utilis is getting third place, and M. cochinchinensis is in the last. This amelioration in oxidative stress parameters was accompanied by a moderate reduction in behavioral abnormalities such as VCM and TPF

RE induced tongue protrusions to seem to be a better model of tardive dyskinesia. Indeed, acute dystonia frequently develops after the first dose of neuroleptic, whereas RE produces a decrease in tongue protrusion in animals observed $6 \mathrm{~h}$ after the first injection (Neisewander et al., 1994, 1996). The increase in tongue protrusion, however, is not observed until $24 \mathrm{~h}$ after the second RE injection or $72 \mathrm{~h}$ after a single injection [37]. In addition, Sussman et al. demonstrated that RE-induced spontaneous oral dyskinesia (i.e., spontaneous increase in TPF) persisted above control level for at least 84 days post-treatment, despite depletion of dopamine in the caudate putamen. These findings suggest that tongue protrusion is not an acute RE-elicited effect, but rather spontaneous oral dyskinesia that develops as a result of a persistent neuropathological change. In our study, the TPF is much lowered by M. pruriens extract at the dose of $300 \mathrm{mg} / \mathrm{kg}$. M. deeringiana and M. cochinchinensis are having nearly equal effect in reducing TPF. $M$. utilis is comparatively less effective in the minimization of TPF. The reduction of VCM is highest in M. pruriens extract, and $M$. deeringiana and $M$. utilis are also having remarkable effect. $M$. cochinchinensis is showing poor performance in bringing down VCM. The content of L-DOPA and neuroprotective antioxidants is more in $M$. pruriens and $M$. utilis. The level of significance of reduction of VCM is higher in these two samples. This confirms the L-DOPA content plays a major role in the treatment of Parkinsonism and the antioxidants complement the activity.

\section{CONCLUSION}

From the present investigation, it is concluded that out of four samples of "Poonaikali," M. pruriens is the authentic and effective drug. Although $M$. cochinchinensis, $M$. deeringiana, and $M$. utilis are adulterants, they could be used as substitutes for M. pruriens. M. pruriens is the authentic and effective drug in the treatment of Parkinson's disease. The L-DOPA content is more in M. pruriens. Further clinical trial is needed to support this conclusion. As on offshoot of this work, an activity guided fraction of $M$. pruriens seeds, isolations, purification, and characterization of compounds in the extracts could be carried out for future work.

\section{REFERENCES}

1. Hussain G, Manyam BV. Mucuna pruriens proves more effective than L-DOPA in Parkinson's disease animal model. Phytotherapy Res 1997;11:419-23.

2. Sian-Hülsmann J, Mandel S, Youdim MB, Riederer P. The relevance of iron in the pathogenesis of Parkinson's disease. J Neurochem 2011;118:939-57.

3. Stoessl JA. Etiology of Parkinson's disease. Can J Neuorol 1999;26:S5- 12.

4. Cheryl HW. Diagnosis and Management of Parkinson's Disease. $6^{\text {th }}$ ed. New York: Professional Communications Inc.; 2008. p. 4-25.

5. Sathiyanarayanan L, Arulmozhi S. Mucuna pruriens Linn.-A comprehensive review. Pharmacogn Rev 2007;1:157-62.

6. Ganthi AS, Vijayambika C, Jegadeesan M. Comparative L-dopa and anti-nutritional contents in seed materials of market samples of Mucuna pruriens (L) DC. Int J Res Ayurveda Pharm 2010;1:480-3

7. Vijayambika C. Pharmacognostical Studies on Mucuna pruriens (L.) DC and its Adulterants. Thanjavur, India: Department of Siddha Medicine, Tamil University; 2003

8. Kay L. The Microscopical Study of Drugs. London, Bailliere: Tindall and Cox; 1938. p. 45.

9. Johnson DA. Plant Microtechnique. New York: McGraw Hill Book Company; 1940. p. 182-3.

10. Birch HF, Doughty LR. The distribution and interrelationships of the alkaloids in the bark of Cinchona ledgeriana. Biochem $\mathrm{J}$ 1948;43:38- 44 .

11. Lowry OH, Rosebrough NJ, Farr AL, Randall RJ. Protein measurement with the folin phenol reagent. J Biol Chem 1951;193:265-75.
12. Seigler DS, Seilheimer S, Keesy J, Huang HF. Tannins from four common Acacia Species of Texas and Northeastern Mexico. Econ Bot 1986;40:220-32.

13. Bray HG, Thorpe WV. Analysis of phenolic compounds of interest in metabolism. Methods Biochem Anal 1954;1:27-52.

14. Abbott B, Starr BS, Starr MS. CY 208-243 behaves as a typical D-1 agonist in the reserpine-treated mouse. Pharmacol Biochem Behav 1991;38:259-63.

15. Vogel WH, Bernward AS, Jürgen S, Günter M, Vogel WF. Drug Discovery and Evaluation Pharmacological Assays. $2^{\text {nd }}$ ed. Berlin, Heidelberg, New York: Springer-Verlag; 2002. p. 577-85.

16. Neisewander JL, Castañeda E, Davis DA. Dose-dependent differences in the development of reserpine-induced oral dyskinesia in rats: Support for a model of tardive dyskinesia. Psychopharmacology (Berl) 1994;116:79-84.

17. Neisewander JL, Castañeda E, Davis DA, Elson HJ, Sussman AN. Effects of amphetamine and 6-hydroxydopamine lesions on reserpineinduced oral dyskinesia. Eur J Pharmacol 1996;305:13-21.

18. Uhrbrand L, Faurbye A. Reversible and irreversible dyskinesia after treatment with perphenazine, chlorpromazide, reserpine and electroconvulsive therapy. Psychopharmacology 1960;1:408-18.

19. Bergamo M, Abílio VC, Queiroz CM, Barbosa-Júnior HN, Abdanur LR, Frussa-Filho R, et al. Effects of age on a new animal model of tardive dyskinesia. Neurobiol Aging 1997; 18:623-9.

20. Krause E, Gürkov R. Local botulinum neurotoxin A therapy in tardive lingual dyskinesia. Laryngorhinootologie 2009;88:508-10.

21. Florang VR, Rees JN, Brogden NK, Anderson DG, Hurley TD, Doorn JA, et al. Inhibition of the oxidative metabolism of 3,4-dihydroxyphenylacetaldehyde, a reactive intermediate of dopamine metabolism, by 4-hydroxy-2-nonenal. Neurotoxicology 2007;28:76-82.

22. Burke WJ, Kumar VB, Pandey N, Panneton WM, Gan Q, Franko MW, et al. Aggregation of alpha-synuclein by DOPAL, the monoamine oxidase metabolite of dopamine. Acta Neuropathol 2008;115:193-203.

23. Kulkarni SK, Naidu PS. Isoniazid induced orofacial dyskinesia in rats: An experimental model for tardive dyskinesia. Indian J Pharmacol 2001;33:286-8.

24. Dutra RC, Andreazza AP, Andreatini R, Tufik A, Vital MA. Behavioral effects of MK-801 on reserpine-treated mice. Progress in Neuro-24. Psychopharmacol Biol Psychiatry 2002;26:487-95.

25. Hornykiewiez O. Dopamine and brain function. Pharmacol Rev 1966;18:925-64.

26. Kasireddy P, Khumanthem D S, Prashanti P, Manguluri P. Neuoprotective potential and efficacy of neurodegenerative disorders of fruit extract of Aegle marmelos. Int J Pharm Pharm Sci 2015;7:155- 9.

27. Colpaert FC. Pharmacological characteristics of tremor, rigidity and hypokinesia induced by reserpine in rat. Neuropharmacology 1987;26:1431-40.

28. Kaur S, Starr MS. Antiparkinsonian action of dextromethorphan in the reserpine-treated mouse. Eur J Pharmacol 1995;280:159-66.

29. Menzaghi F, Whelan KT, Risbrough VB, Rao TS, Lloyd GK. Interactions between a novel cholinergic ion channel agonist, SIB$1765 \mathrm{~F}$ and L-DOPA in the reserpine model of Parkinson's disease in rats. J Pharmacol Exp Ther 1997;280:393-401.

30. Skalisz LL, Beijamini V, Joca SL, Vital MA, Da Cunha C, Andreatini R, et al. Evaluation of the face validity of reserpine administration as an animal model of depression-parkinson's disease association. Prog Neuropsychopharmacol Biol Psychiatry 2002;26:879-83.

31. Javid M, Archana P. Evaluation of anti-obesity effect of aqueous extract of Mucuna pruriens seeds on rats. Int J Pharm Pharm Sci 2017;9:111-5.

32. Fachinetto R, Burger ME, Wagner C, Wondracek DC, Brito VB, Nogueira $\mathrm{CW}$, et al. High fat diet increases the incidence of orofacial dyskinesia and oxidative stress in specific brain regions of rats. Pharmacol Biochem Behav 2005;81:585-92.

33. Pivovarova NB, Nguyen HV, Winters CA, Brantner CA, Smith CL, Andrews SB. Excitotoxic calcium overload in a subpopulation of mitochondria triggers delayed death in hippocampal neurons. J Neurosci 2004;16:5611-2.

34. Hernández-Fonseca K, Cárdenas-Rodríguez N, Pedraza-Chaverri J, Massieu L. Calcium-dependent production of reactive oxygen species is involved in neuronal damage induced during glycolysis inhibition in cultured hippocampal neurons. J Neurosci Res 2008;86:1768-80.

35. Windelborn JA, Lipton P. Lysosomal release of cathepsins causes ischemic damage in the rat hippocampal slice and depends on NMDAmediated calcium influx, arachidonic acid metabolism, and free radical production. J Neurochem 2008;106:56-9.

36. Lukic-Panin V, Kamiya T, Zhang H, Hayashi T, Tsuchiya A, Sehara Y, 
et al. Prevention of neuronal damage by calcium channel blockers with antioxidative effects after transient focal ischemia in rats. Brain Res 2007;1176:143-50
37. Sussman AN, Tran-Nguyen LT, Neisewander JL. Acute reserpine administration elicits long-term spontaneous oral dyskinesia. Eur J Pharmacol 1997;337:157-60. 